\title{
Photoactivity of Titanium Dioxide Foams
}

\author{
Maryam Jami $\mathbb{D},{ }^{1}$ Ralf Dillert, ${ }^{1}$ Yanpeng Suo $\mathbb{D}^{1},{ }^{1}$ Detlef $W$. Bahnemann, ${ }^{1,2}$ \\ and Michael Wark ${ }^{3}$ \\ ${ }^{1}$ Institut für Technische Chemie, Leibniz Universität Hannover, Callinstraße 3, 30167 Hannover, Germany \\ ${ }^{2}$ Laboratory "Photoactive Nanocomposite Materials", Saint Petersburg State University, Ulyanovskaya Str. 1, Peterhof, \\ Saint Petersburg 198504, Russia \\ ${ }^{3}$ Technische Chemie, Universität Oldenburg, Carl-von-Ossietzky Str. 9-11, 26111 Oldenburg, Germany
}

Correspondence should be addressed to Maryam Jami; jamimaryam@ymail.com

Received 17 October 2017; Revised 7 January 2018; Accepted 4 February 2018; Published 10 April 2018

Academic Editor: Leonardo Palmisano

Copyright $\odot 2018$ Maryam Jami et al. This is an open access article distributed under the Creative Commons Attribution License, which permits unrestricted use, distribution, and reproduction in any medium, provided the original work is properly cited.

$\mathrm{TiO}_{2}$ foams have been prepared by a simple mechanical stirring method. Short-chain amphiphilic molecules have been used to stabilize colloidal suspensions of $\mathrm{TiO}_{2}$ nanoparticles. $\mathrm{TiO}_{2}$ foams were characterized by X-ray diffraction (XRD), X-ray photoelectron spectroscopy (XPS), UV-vis absorption spectroscopy, and scanning electron microscopy (SEM). The photoassisted oxidation of NO in the gas phase according to ISO 22197-1 has been used to compare the photoactivity of the newly prepared $\mathrm{TiO}_{2}$ foams to that of the original powders. The results showed that the photoactivity is increased up to about $135 \%$. Foam structures seem to be a good means of improving the photoactivity of semiconductor materials and can readily be used for applications such as air purification devices.

\section{Introduction}

Heterogeneous photocatalysis has been used as an effective technique for the remediation of chemical wastes. Titanium dioxide $\left(\mathrm{TiO}_{2}\right)$ is one of the most frequently investigated heterogeneous semiconductor photocatalysts and has been shown to be a relatively cheap and effective material to decompose various kinds of organic and inorganic wastes in both, the liquid and the gas phase [1-4]. As one of the most promising applications, the decomposition of nitrogen oxides $\left(\mathrm{NO}_{\mathrm{x}}\right)$ in ambient air has been studied intensively. Nitrogen oxides (mainly $\mathrm{NO}$ and $\mathrm{NO}_{2}$ ), which are emitted from sources such as automobiles and boilers, have become a serious environmental problem in urban areas and can also cause ozone depletion, photochemical smog, and acid deposition. Substantial efforts have been undertaken to develop methods to reduce the concentration of $\mathrm{NO}$ and of $\mathrm{NO}_{2}$. In particular, the photoassisted oxidation of $\mathrm{NO}_{\mathrm{x}}$ to nitric acid $\left(\mathrm{HNO}_{3}\right)$ using $\mathrm{TiO}_{2}$ seems to be an effective, economical, and energy saving process for the treatment of diluted $\mathrm{NO}_{\mathrm{x}}[5-10]$.
The photocatalytic properties of $\mathrm{TiO}_{2}$ materials do not just depend on the chemical composition but also on the geometrical microstructure $[11,12]$. During the last few decades, there have been numerous reports focusing on methods to enhance the photoactivity of $\mathrm{TiO}_{2}$ materials $[13,14]$. Several research groups have been working on the doping of $\mathrm{TiO}_{2}$ with noble metals ( $\mathrm{Au}, \mathrm{Pd}, \mathrm{Ag}$, and $\mathrm{Pt}$ ) or nonmetal atoms $(\mathrm{N}, \mathrm{F}, \mathrm{S}, \mathrm{C})$. All these investigations have developed our knowledge concerning $\mathrm{TiO}_{2}$-based photocatalysts and have generated very interesting and important results in this research area. However, in general, the $\mathrm{TiO}_{2}$-based photocatalysts suffer from rather low quantum efficiencies because of poor photoabsorption efficiencies and weak molecular transport capabilities [5, 15-22].

Another strategy to enhance the photoactivity of $\mathrm{TiO}_{2}$ materials is the creation of new geometrical microstructures. It has, for example, been reported that the photoactivity of $\mathrm{TiO}_{2}$ with structural, that is, ordered porosity is higher than that of nanoparticular $\mathrm{TiO}_{2}$ with only interparticular nanovoids. Materials with structural porosity have high surface areas, and all pores are well interconnected. The macro- 


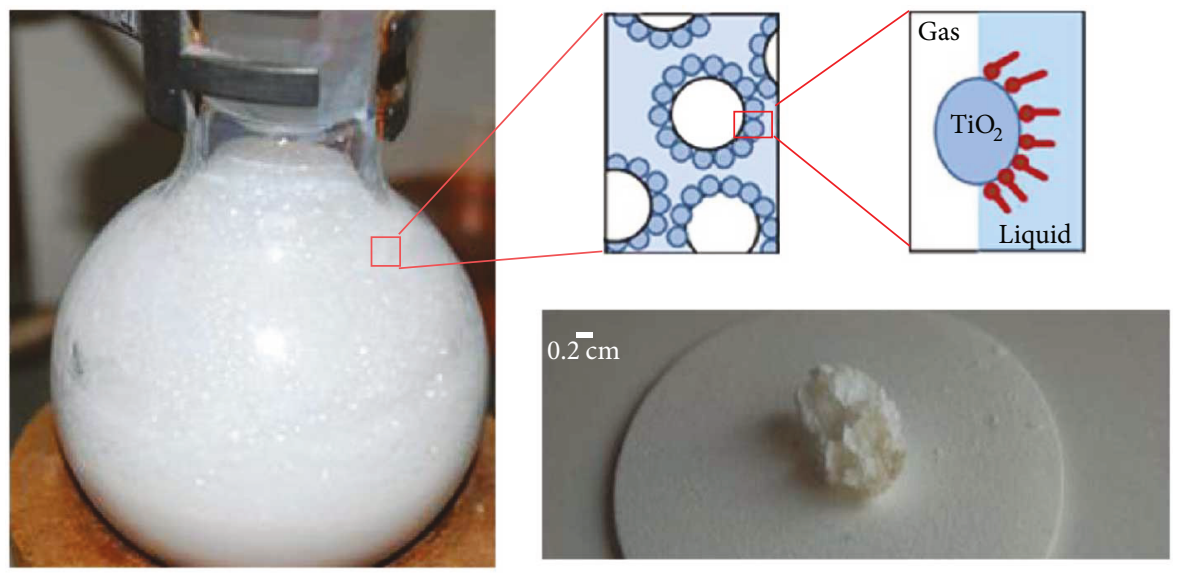

Figure 1: Photographs of wet particle-stabilized foams and a schematic illustration of the stabilization of gas bubbles with partially hydrophobized colloidal particles to finally obtain the $\mathrm{TiO}_{2}$ foam.

and mesoporosity improves the adsorption and diffusion of reactants and products. The existence of cavities furthermore increases the light-capturing efficiency because of their strong light-scattering properties [21, 23-27].

Titanium dioxide foams have shown to have a higher photoactivity as the powder one by Zhao et al. [24]. However, it is not clear how the foam structure affected the photoactivity. One reason could be changes in the surface properties of $\mathrm{TiO}_{2}$. Further investigation is necessary to confirm this theory. Photocatalytic deposition velocity is known to be an input value that predicts the possible effect of photocatalytically active surfaces on air pollution in urban areas.

In this article, it is reported that $\mathrm{TiO}_{2}$ foams have been prepared by a simple mechanical stirring method employing short-chain amphiphilic molecules to surface-lyphobize commercially available $\mathrm{TiO}_{2}$ nanoparticles. The aims of this work were to study the photoactivity and the changes in the surface properties of $\mathrm{TiO}_{2}$ foams prepared in this way and compare it to that of the starting $\mathrm{TiO}_{2}$ powder. In 2007, ISO published a standard test to evaluate the photoassisted oxidation efficiency of the air-cleaning products. The photoassisted degradation of $\mathrm{NO}$ in the gas phase according to ISO 22197-1 was used as the test reaction to compare the photoactivity of the $\mathrm{TiO}_{2}$ foams to that of the original powders. Photocatalytic deposition velocities were determined to describe the changes in the surface properties. The morphology and the structural properties of $\mathrm{TiO}_{2}$ foams have also been studied.

\section{Experimental}

2.1. Materials. Commercial titanium dioxide Evonik AERO$\mathrm{XIDE}^{\circledR}$ P25 (30\% rutile, 70\% anatase, $20-30 \mathrm{~nm}$ ) has been used as received. Hexylic acid (hexanoic acid) and hexylamine from Sigma-Aldrich have been used as short-chain amphiphilic molecules. Other chemicals used in the experiments were deionized water and sodium hydroxide (Sigma-Aldrich).

2.2. Foam Preparation. Titanium dioxide foams were prepared according to the method described by Zhao et al.
[24]. In short, $2 \mathrm{~g}$ of P25 was added stepwise to water under vigorous stirring for 20 minutes. The $\mathrm{pH}$ value of the suspension was around 3.6. The suspension was homogenized for about 30 min using an Ultrasonic Vibra-Cell. Meanwhile, a solution containing short-chain amphiphilic molecules ( $0.3 \mathrm{~g}$ hexylic acid in water, the ratio of $\mathrm{TiO}_{2}$ to amphiphilic molecules was adapted from [24]), was prepared. This solution was then added dropwise to the $\mathrm{TiO}_{2}$ suspension under vigorous stirring for $30 \mathrm{~min}$.

The $\mathrm{pH}$ was adjusted to $\mathrm{pH} 3.5$ with $0.1 \mathrm{M} \mathrm{NaOH}$ if necessary (in case of using hexylic acid as amphiphilic agent). Finally, the wet $\mathrm{TiO}_{2}$ foam was produced and this wet foam was air dried for one day at room temperature. Figure 1 shows photographs of freshly prepared wet $\mathrm{TiO}_{2}$ foam and of a dry one.

2.3. Characterization. The crystal structures of the samples were determined by $\mathrm{X}$-ray powder diffraction at room temperature using $\mathrm{Cu} \mathrm{K} \alpha$ radiation on a Bruker D8 Advance diffractometer in the $2 \theta$ range of $10-80^{\circ}$. The particle size distributions were calculated from the peak broadening of the XRD patterns using the Scherrer equation [28]. X-ray photoelectron spectroscopy (XPS) measurements were carried out using a Thermo Fisher ESCALAB 250Xi equipped with monochromatic Al-K $\alpha$ X-ray source $(1486.6 \mathrm{eV})$. The binding energies (BE) were referenced to the adventitious carbon contamination C 1 s peak $(284.8 \mathrm{eV})$. High-resolution XPS spectra of Ti $2 p, O 1 s$, and $\mathrm{C} 1 \mathrm{~s}$ were recorded with $10 \mathrm{eV}$ pass energy, and $0.02 \mathrm{eV}$ step size with 5 spectra was averaged.

A scanning electron microscope (SEM) (JEOL JSM$6700 \mathrm{~F}$ field-emission) was used to characterize the morphology of the $\mathrm{TiO}_{2}$ foams, and the Varian Cary 4000 UV-vis spectrophotometer was used to measure the diffuse reflectance spectra of the samples. Band gap energies were calculated by using Tauc plots resulting from the Kubelka-Munk transformation of the respective diffuse reflectance spectra. The nitrogen sorption isotherms were measured at $77 \mathrm{~K}$ using a Quantachrome Autosorb 3. The foam samples were outgassed in vacuum at $25^{\circ} \mathrm{C}$ and $\mathrm{P} 25-\mathrm{TiO}_{2}$ at $100^{\circ} \mathrm{C}$ for 24 hours prior the sorption measurement. The sorption data were analyzed with the quantachrome software ASiQwin 2.0. 


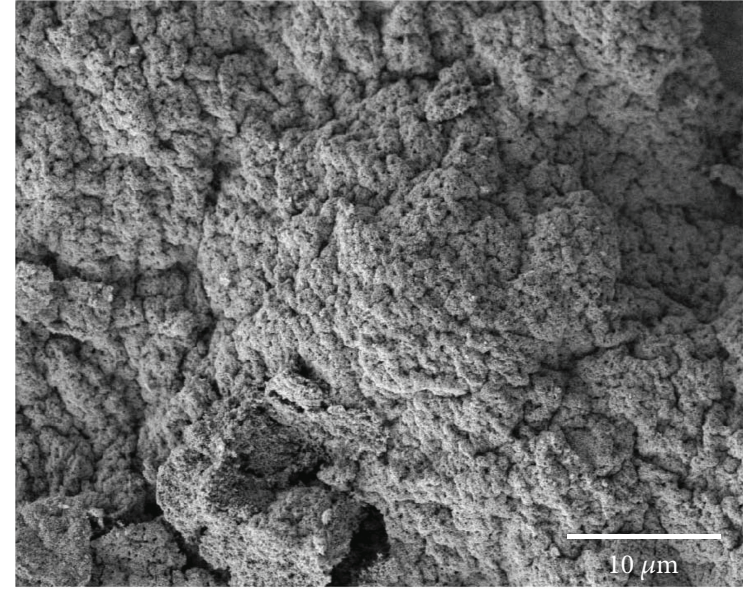

(a)

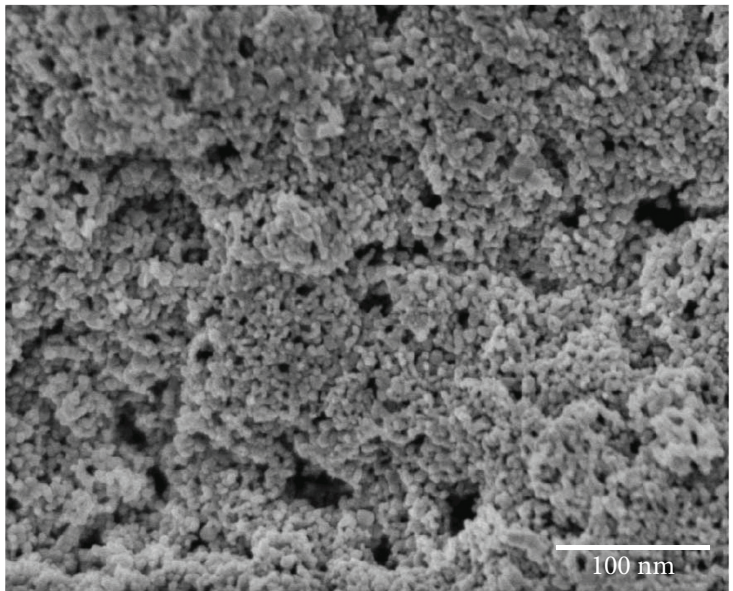

(b)

FIgURE 2: SEM pictures of the prepared $\mathrm{TiO}_{2}$ foam with $\mathrm{P} 25$ as $\mathrm{TiO}_{2}$ nanoparticle. The bar is $10 \mu \mathrm{m}$ for the low-magnification image (a) and $100 \mathrm{~nm}$ for the high-magnification image (b).

2.4. Photoassisted Oxidation of NO. The photoassisted oxidation of NO was measured according to ISO 22197-1 [29]. The experimental details were described previously $[9,10,30]$. Briefly, the test equipment included the test gas supply, a humidifier, three mass flow controllers (Brooks Instrument), a photoreactor, a light source (Philips, Cleo Compact, $l_{\max }=355 \mathrm{~nm}, 15 \mathrm{~W}$ ), and a chemiluminescent $\mathrm{NO}-\mathrm{NO}_{\mathrm{x}}$ analyzer (Horiba APNA 360). The concentration of the probe gas was followed by a $\mathrm{NO} / \mathrm{NO}_{2}$ analyzer in the dark until equilibrium was reached. The probe gas mixture had a concentration of $1 \mathrm{ppm}_{\mathrm{v}} \mathrm{NO}$ (Linde, $50 \mathrm{ppm}_{\mathrm{v}} \mathrm{NO}$ in $\mathrm{N}_{2}$ ), a relative humidity of $50 \%$, and a laminar volume flow $\dot{V}$ of $5 \times 10^{-5} \mathrm{~m}^{3} / \mathrm{s}$. For a single degradation test, $\mathrm{TiO}_{2}$ foam or the P25 sample was placed into the photoreactor with a geometric surface area of $18.49 \mathrm{~cm}^{2}$ and covered with a UV(A) transparent borosilicate glass. The NO concentration was adjusted in the dark via a bypass mode followed by a dark adsorption of the pollutant on the sample surface by switching from bypass to reaction mode. After equilibration, the degradation of $\mathrm{NO}$ was followed under irradiation (light intensity $10 \mathrm{~W} / \mathrm{m}^{2}$ ) for $2 \mathrm{~h}$ until a steady state was reached. Subsequently, the system was kept in the dark until the initial concentration of NO was achieved again. For the determination of the photocatalytic deposition velocity use, a photoreactor with a geometric surface area of $39.6 \mathrm{~cm}^{2}$ and the amount of the probe gas (NO) have been changed during the photoassisted oxidation. The NO concentration varied between $0.1 \mathrm{ppm}_{\mathrm{v}}$ and $1.0 \mathrm{ppm}_{\mathrm{v}}$. The flow rate of the probe gas $\left(5 \times 10^{-5} \mathrm{~m}^{3} / \mathrm{s}\right)$, the temperature $\left(25^{\circ} \mathrm{C}\right)$, and the relative humidity (50\%) inside the photoreactor were kept constant.

\section{Results and Discussions}

3.1. $\mathrm{TiO}_{2}$ Foam Characterization. The scanning electron microscopy (SEM) images of the $\mathrm{TiO}_{2}$ foam show a porous, spongy, and rough morphology. The photograph and the low magnification image of the foam reveal macroporosity (Figure 2). The pore size distribution of the foams depends on the type of amphiphilic agent that has been used. For example, $\mathrm{TiO}_{2}$-foam-1 (with hexylic acid) has an average pore size of approx. $0.24 \pm 0.09 \mathrm{~cm}$ and $\mathrm{TiO}_{2}$-foam-2 (with hexylamine) has an average pore size of approx. 0.11 $\pm 0.04 \mathrm{~cm}$. These large pores with extended networks provide many canals for diffusion of reactants. With increasing SEM magnification, the primary $\mathrm{TiO}_{2}$ nanoparticles can be imaged (particle size distribution: 20-30 nm). Supplementary 1 presents the SEM photographs of $\mathrm{TiO}_{2}-\mathrm{P} 25, \mathrm{TiO}_{2}$-foam-1, and $\mathrm{TiO}_{2}$-foam-2.

The UV-vis diffuse reflectance spectra (Supplementary Material, Fig. S2) from P25 and from the $\mathrm{TiO}_{2}$-foam-1 have been measured, and the energy band gaps of the materials were obtained using the Kubelka-Munk function. The band gap energy of the materials was not changed $\left(E_{\mathrm{g}} \sim 3.2 \mathrm{eV}\right)$ indicating that the semiconductor properties of the $\mathrm{TiO}_{2}$ foam are same as those of the $\mathrm{TiO}_{2}$ powder.

BET surface areas have been determined from the $\mathrm{N}_{2}$ adsorption/desorption measurements (see Supplementary Material, Fig. S3). There is no big difference between BET surface areas of the P25 and to those of $\mathrm{TiO}_{2}$-foam-2 (with hexylamine). P25 shows a surface area of $58.9 \pm 1.8 \mathrm{~m}^{2} \cdot \mathrm{g}^{-1}$ whereas $\mathrm{TiO}_{2}$-foam-1 (with hexylic acid) has a surface area of $51.7 \pm 1.6 \mathrm{~m}^{2} \cdot \mathrm{g}^{-1}$ and $\mathrm{TiO}_{2}$-foam-2 (with hexylamine) has a surface area of $58.1 \pm 2.5 \mathrm{~m}^{2} \cdot \mathrm{g}^{-1}$. Based on the experimental data, we recognize that the nitrogen sorption is not a suitable method to determine the pore size distribution of our foams. It is obvious that the $\mathrm{TiO}_{2}$ foams have large pore size which this method could not determine.

Figure 3 shows the XRD pattern of the $\mathrm{TiO}_{2}$ foam. This $\mathrm{XRD}$ pattern is, as expected, consistent with the anatase and rutile crystal phases of $\mathrm{TiO}_{2}$ (JCPDS file number anatase: 00-0210-1272; rutile: 01-070-7347). The three characteristic sharp peaks at $2 \theta=25.2^{\circ}, 37.7^{\circ}$, and $48.0^{\circ}$ correspond to the (101), (044), and (200) planes of the anatase phase, respectively, and the peaks at $2 \theta=27.4^{\circ}, 54.3^{\circ}$, and $36.0^{\circ}$ fit to the (110), (211), and (101) planes of the rutile phase, respectively. The average particle sizes of the $\mathrm{TiO}_{2}$ nanoparticles in the foam were calculated using the Scherrer equation yielding approx. $17 \mathrm{~nm}$ for anatase and $20 \mathrm{~nm}$ for rutile, which is in 


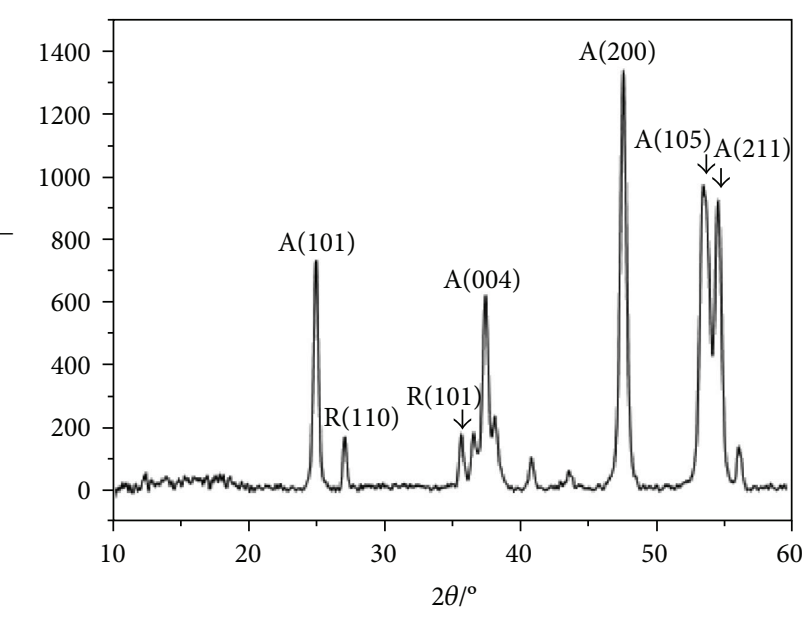

FIGURE 3: XRD pattern of the as-prepared $\mathrm{TiO}_{2}$ foam. It is a mixture of anatase (A) and rutile (R) crystal phases.

agreement with the SEM observations. Supplementary 4 presents a comparison between the XRD pattern of $\mathrm{TiO}_{2}$-foam-1 with original used P25 (Fig. S4) and the XRD pattern of all three samples $\left(\mathrm{TiO}_{2}-\mathrm{P} 25, \mathrm{TiO}_{2}\right.$-foam-1, and $\mathrm{TiO}_{2}$-foam-2; Fig. S5). All three samples have the same crystal structure, which is a mixture of anatase and rutile phases.

The surface composition and chemical states of the $\mathrm{TiO}_{2}-$ foam- 1 and the starting $\mathrm{TiO}_{2}$ powder (P25) were investigated by XPS. The survey spectra for both samples show exclusively the presence of $\mathrm{C}, \mathrm{O}$, and $\mathrm{Ti}$ (see Figure 4(a)). The Ti $2 \mathrm{p}$ photoelectron line (Figure $4(\mathrm{~b})$ ) consists of the $\mathrm{Ti} 2 \mathrm{p}_{3 / 2}$ and $\mathrm{Ti}$ $2 \mathrm{p}_{1 / 2}$ doublets at binding energies of $458.9(459 \mathrm{eV})$ and $464.6(464.7 \mathrm{eV})$, respectively. These values are closely related to the reported $\mathrm{Ti} 2 \mathrm{p}$ lines ranging $458.5-459.5 \mathrm{eV}$ and $464.2-464.7 \mathrm{eV}$, respectively $[31,32]$.

The peak separation $(\sim 5.7 \mathrm{eV})$ and the strong satellite peak $14 \mathrm{eV}$ above the main line indicate the $\mathrm{Ti}^{4}$ oxidation state. The main O 1s line (Figure 4(c)) is located at 530.1 $(530.2 \mathrm{eV})$ assigned to the lattice oxygen with additional broad peak centered at $531.1(530.9 \mathrm{eV})$ related to low coordinated surface $\mathrm{O}$ atoms (with low electron density than the lattice $\mathrm{O}^{2-}$ ions), respectively (PCCP 2000, 2, 1319-1324). The $\mathrm{Ti}: \mathrm{O}$ ratios were found to be 0.48 and 0.52 for the $\mathrm{TiO}_{2}$ foam and the $\mathrm{P} 25$, respectively.

3.2. Photoactivity of $\mathrm{TiO}_{2}$ Foams. The photoassisted degradation of NO in the gas phase was used to compare the photoactivity of the $\mathrm{TiO}_{2}$ foams to that of the original powders (P25). The mechanism and kinetics of this reaction have been studied intensively before $[9,10]$. It has been reported that using Degussa P25 as a catalyst, the determination of the reaction rate by the Langmuir-Hinshelwood model has some limitations. Wang et al. reported about the effect of variations of the inlet NO concentrations. Their observations showed that the reaction is first-order at low concentrations and zero-order at high concentrations [31, 32]. Studies conducted by Dillert et al. have shown that the $\mathrm{NO}$ oxidation at $\mathrm{TiO}_{2}$ surfaces also depends on the light intensity. According to their analysis, the rates of the photocatalytic NO oxidation on $\mathrm{UV}(\mathrm{A})$-irradiated $\mathrm{TiO}_{2}$ samples at varying nitrogen(II) oxide concentrations and photon fluxes and possibly at varying humidity can be predicted by a mathematical model [10].

Figure 5 shows the concentration changes of $\mathrm{NO}, \mathrm{NO}_{2}$, and $\mathrm{NO}_{\mathrm{x}}$ as a function of UV illumination time during the photoassisted oxidation of $\mathrm{NO}$ with employing AEROXIDE P25 and $\mathrm{TiO}_{2}$ foam, respectively, under the same conditions. The typical experimental data for NO oxidation can be divided into four zones. Zone A is characterized by the adjustment of the NO concentration ( $1 \mathrm{ppm}$ ) before UV light illumination. Zone $\mathrm{B}$ is characterized by the adsorption of NO in the dark followed by the saturation of the surface of the photocatalyst sample. Once there is no further change in the NO concentration, the light source can be switched on to start the photocatalytic reaction (Zone C). After $2 \mathrm{~h}$ of irradiation with UV light, the light source is switched off (Zone D).

The photoassisted oxidation of NO is assumed to be a surface reaction mediated between $\mathrm{NO}$ and photogenerated hydroxyl radicals. And its mechanism has been already investigated. The three major steps during the photoassisted oxidation are oxidation of $\mathrm{NO}$ to $\mathrm{HNO}_{2}$, oxidation of $\mathrm{HNO}_{2}$ to $\mathrm{NO}_{2}$ (in the transient state), and finally oxidation of $\mathrm{NO}_{2}$ to $\mathrm{HNO}_{3}$. If the catalyst is saturated with $\mathrm{HNO}_{3}$, a steady state is attained and the oxidation reaction can go only as far as to $\mathrm{NO}_{2}[2,9,10,33,34]$.

Considering the reaction dynamics during the entire photocatalytic process, the photocatalytic efficiency is determined by the number of photogenerated charge carriers which can avoid the recombination reaction. The photonic efficiency $(\zeta)$ of the NO degradation is calculated from the degradation rate of $\mathrm{NO}$ and the incident photon flux according to the following equation [33]:

$$
\text { Photonic efficiency }(\zeta)=\frac{\text { degradation rate }}{\text { incident photon flux }} \text {. }
$$

The incident photon flux $\left(J_{0}\right)$ is calculated based on (2) with its value being $5 \times 10-8 \mathrm{~mol} \cdot \mathrm{s}-1$ (UV-A light intensity $1 \mathrm{~mW} \cdot \mathrm{cm}^{-2}$, average illumination wavelength $\lambda=350 \mathrm{n}$ $\mathrm{m}$, irradiated surface area $18.49 \mathrm{~cm}^{2}, N_{\mathrm{A}}$ Avogadro number, $h$ Planck constant, and $c$ light velocity).

$$
J_{0}=\frac{I A_{\mathrm{r}} \lambda}{N_{\mathrm{A}} h c}
$$

where $I$ is the UV-A light intensity $\left(1 \mathrm{~mW} \cdot \mathrm{cm}^{-2}\right), A_{\mathrm{r}}$ is the illuminated surface area $\left(18.49 \mathrm{~cm}^{2}\right), \lambda$ is the average illumination wavelength $(350 \mathrm{~nm}), N_{\mathrm{A}}$ denotes Avogadro number; $h$ denotes Planck constant; and $c$ denotes light velocity.

The degradation rate of NO is calculated using the following equation (where $q_{\mathrm{V}}$ is the volumetric flow rate):

$$
\frac{\Delta n_{\mathrm{NO}}}{\Delta t}=\left(c_{\mathrm{NO}, \text { in }}-c_{\mathrm{NO}, \mathrm{out}}\right) q_{\mathrm{V}} \cdot \frac{P}{R T}
$$

The results are summarized and tabulated in Table 1 . In this table, the results are presented as degraded concentration $\left(C_{\text {gas }}\right.$ in $\left.\mathrm{ppm}\right)$, calculated degradation rate $\left(\Delta n_{\mathrm{NO}} / \Delta t\right.$ in mol.s $\left.{ }^{-1}\right)$, and as photonic efficiency $(\zeta$ in \%). The photonic efficiency $(\zeta \%)$ for the complete degradation of the incoming 


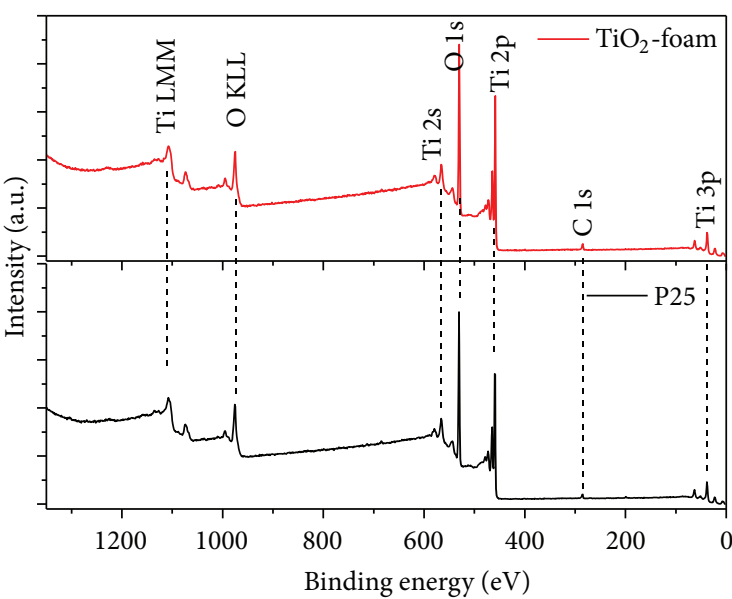

(a)

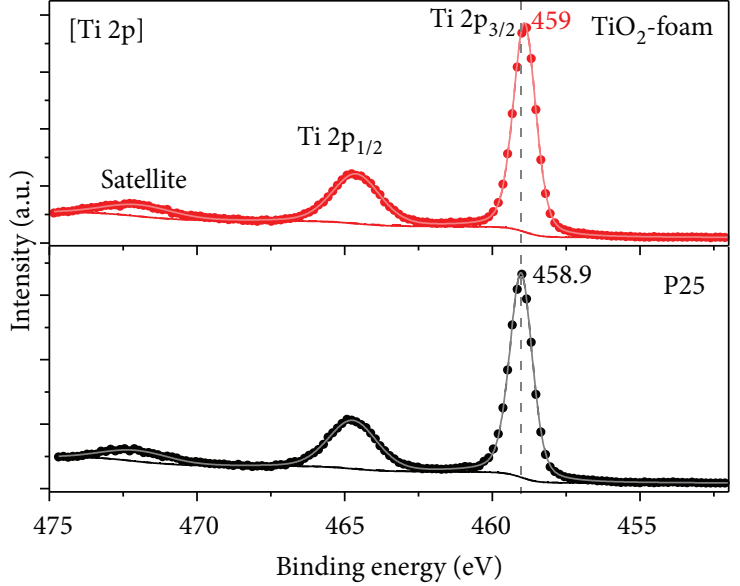

(b)

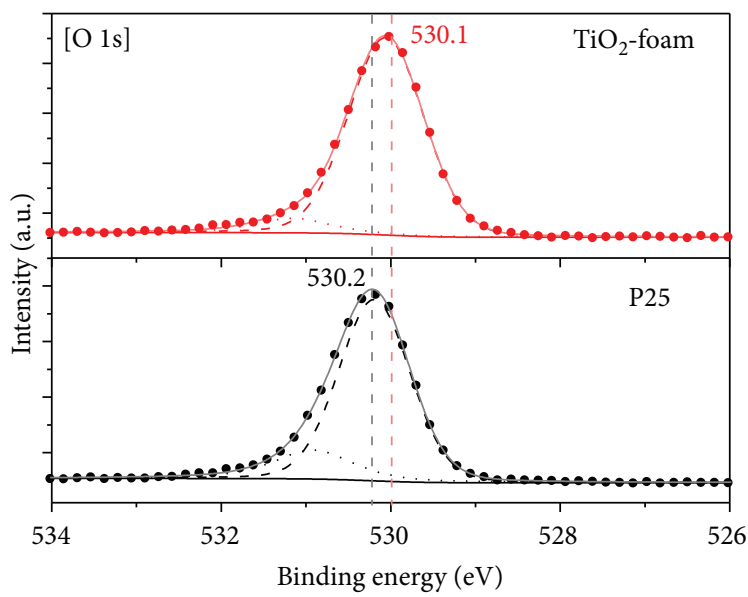

(c)

Figure 4: (a) XPS survey spectra of $\mathrm{TiO}_{2}$-foam-1 and $\mathrm{TiO}_{2}$-P25. (b) Ti $2 \mathrm{p}$ photoelectron line. (c) $\mathrm{O}$ 1s line.

NO gas under ISO 22197-1 conditions for a sample with a surface area of $18.49 \mathrm{~cm}^{2}$ is approx. $4 \%$ (for a sample with a surface area of $50 \mathrm{~cm}^{2}$, it is $1.43 \%$ ).

From the results presented in Table 1, the following conclusions can be drawn: the $\mathrm{TiO}_{2}$-foam-1 (using hexylic acid as amphiphilic molecule) adsorbs more $\mathrm{NO}$ than $\mathrm{P} 25$ powder and produces more $\mathrm{NO}_{2}$ and $\mathrm{NO}_{\mathrm{x}}\left(\mathrm{HNO}_{3}\right)$. This could be an indication of the activity of $\mathrm{TiO}_{2}$ foams under the UV illumination. And also it shows that the foam structures are photocatalytically more active than the original powders.

Engel et al. [30] published an experimental method for the determination of the photocatalytic deposition velocity. To gain more information about our samples and their differences, we used this method. For this investigation, we prepared two different $\mathrm{TiO}_{2}$ foams (using different amphiphilic molecule) and change the amount of the probe gas (NO) during the photoassisted oxidation. The following equation has been used to calculate photocatalytic deposition velocity:

$$
\frac{\ln c_{\mathrm{NO}, \text { out }} / c_{\mathrm{NO}, \text { in }}}{c_{\mathrm{NO}, \text { out }}-c_{\mathrm{NO}, \text { in }}}=A k i K i \cdot \frac{A_{\mathrm{r}}}{q_{\mathrm{V}}\left(c_{\mathrm{NO}, \text { out }}-c_{\mathrm{NO}, \text { out }}\right)}-K i .
$$

This equation is a linear equation of the two variables $\ln \left(c_{\mathrm{NO}, \text { out }} / c_{\mathrm{NO}, \text { in }}\right) /\left(c_{\mathrm{NO}, \text { out }}-c_{\mathrm{NO}, \text { in }}\right)$ and $A_{\mathrm{r}} /\left(q_{\mathrm{V}}\left(c_{\mathrm{NO}, \text { out }}-\right.\right.$ $\left.c_{\text {NO,out }}\right)$ ) having the slope $A k i K i$ and the intercept with the ordinate $K_{i}$. With the calculation of the slope, the photocatalytic deposition velocity will be determined.

Figure 6 presents the change of the NO concentration at the reactor outlet during irradiation of AEROXIDE P25, $\mathrm{TiO}_{2}$-foam-1(with hexylic acid), and $\mathrm{TiO}_{2}$-foam-2 (with hexylamine) with varying $\mathrm{NO}$ inlet concentrations. All other experimental parameters, that is, temperature, relative humidity, and UV (A) photon flux, were kept constant during these experimental runs. With the value of illumination surface area $A_{\mathrm{r}}\left(3.96 \cdot 10^{-3} \mathrm{~m}^{2}\right)$, the volumetric flow rate $q_{\mathrm{V}}\left(3.0 \mathrm{~L} \mathrm{~min}^{-1}\right)$, and the measured values of the NO inlet and outlet concentration, the values of the two variables of (4) have been calculated and plotted for each individual experimental run. These plots clearly show that the $\mathrm{TiO}_{2}$-foam-2 (with hexylamine) has the more active surface for the NO oxidation and both foams are photocatalytically more active than the original powders.

The photoactivity depends on various factors such as the employed catalyst, the light collection efficiency, and the rate 


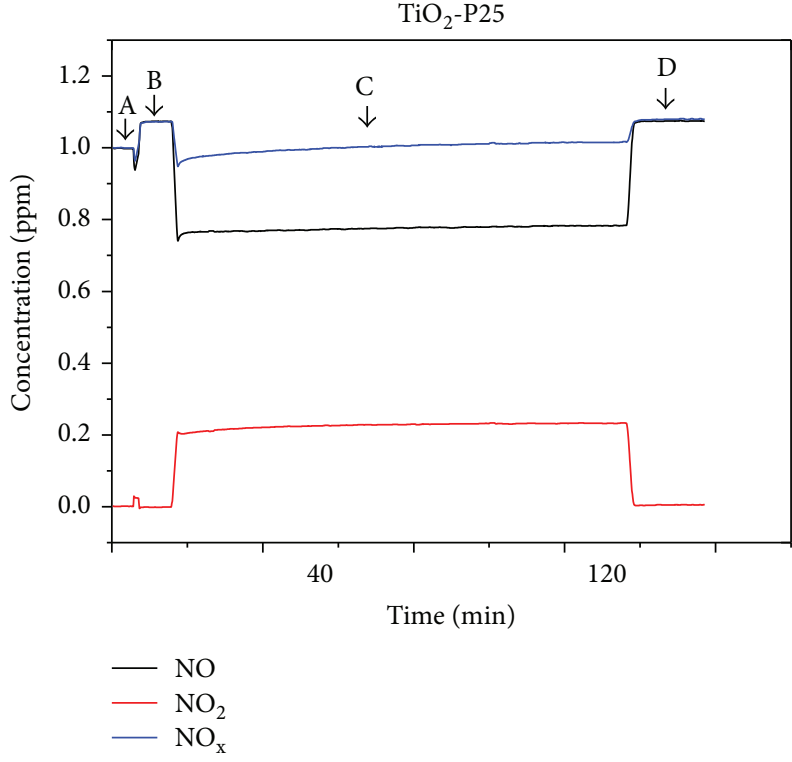

(a)

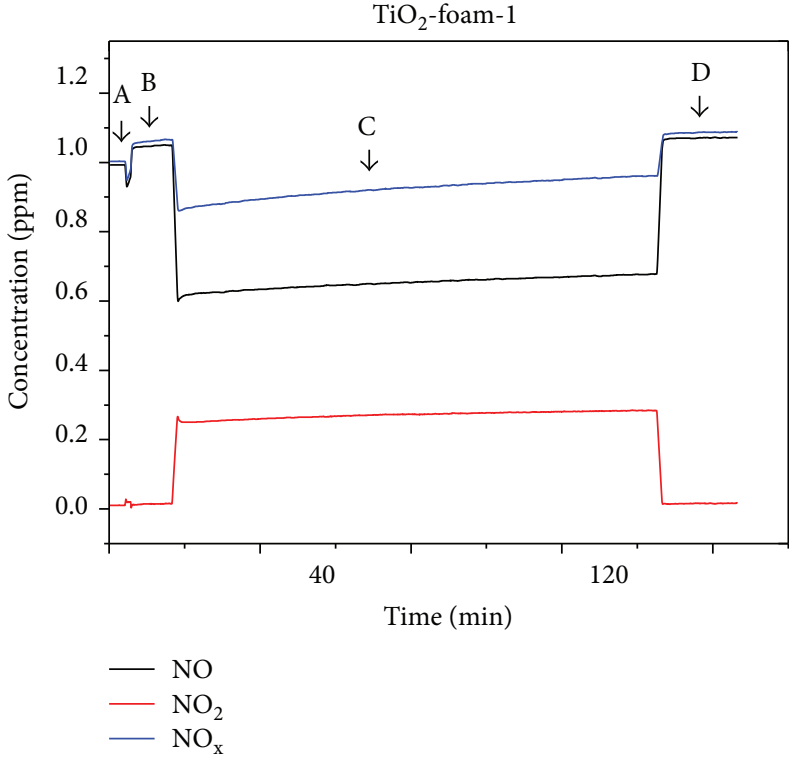

(b)

FIgURE 5: Concentration changes of $\mathrm{NO}, \mathrm{NO}_{2}$, and $\mathrm{NO}_{\mathrm{x}}$ as a function of $\mathrm{UV}$ illumination time in a typical experimental run for a AEROXIDE P25 (a) and $\mathrm{TiO}_{2}$-foam-1 (with hexylic acid) sample (b).

TABlE 1: Concentration changes and calculated photonic efficiencies $(\zeta \%)$.

\begin{tabular}{lccccc}
\hline Sample & $\begin{array}{c}\Delta C_{\mathrm{NO}} \\
(\mathrm{ppm})\end{array}$ & $\begin{array}{c}\Delta C_{\mathrm{NO}_{\mathrm{x}}} \\
(\mathrm{ppm})\end{array}$ & $\begin{array}{c}\Delta C_{\mathrm{NO} 2} \\
(\mathrm{ppm})\end{array}$ & $\begin{array}{c}\Delta n_{\mathrm{NO}} / \Delta t \\
\left(10^{-10} \mathrm{~mol} \cdot \mathrm{S}^{-1}\right)\end{array}$ & $\zeta \%$ \\
\hline $\mathrm{TiO}_{2} \mathrm{P} 25$ & 0.3 & 0.1 & 0.2 & 6.26 & 1.4 \\
$\begin{array}{l}\mathrm{TiO}_{2}- \\
\text { foam-1 }\end{array}$ & 0.5 & 0.2 & 0.3 & 10.4 & 1.9 \\
\hline
\end{tabular}

${ }^{*}$ Hexylic acid as amphiphilic molecule.

of molecular diffusion [7, 33, 35]. The activities of catalysts with the same chemical compositions (P25) have been compared (Table 1 and Figure 5). The light intensity for all experiments was the same although the light collection by the catalyst could be influenced by its structure. The interesting point from our results is that due to the macroporous/mesoporous structure of the foam, the photocatalyst did not own large surface area. The $\mathrm{N}_{2}$ sorption results could not show big difference between the surface area of P25 and that of the foams. Although there is no big difference between the surface areas, the foam structures show more photoactivity.

$\mathrm{TiO}_{2}$ foam shows high photoactivity due to the structure of macroporous/mesoporous channels that provide fast intraparticle molecular transfers, which improves the light harvesting and the adsorption of reactant molecules. This macroporous/mesoporous structure also provides proper interfaces for a facile interparticle charge transfer while the reactants can freely diffuse through the pores. At the same time, the light absorption and the energy transfer through the foam structure into the inner surface of the macroporous/mesoporous $\mathrm{TiO}_{2}$ are apparently as high as expected.
It has been shown that mass transfer and surface reactions control heterogeneous catalytic reactions $[10,36]$. Yang et al. [35] reported that the mass transfer coefficient is affected by the flow velocity. Beyond a certain flow velocity, the photocatalytic reaction process was founded to be independent of the mass transfer and was only controlled by the surface reactions. In this work, the value of the flow velocity is rather high and identical for all reactions. Therefore, the photocatalytic process is apparently independent of any mass transfer limitations and will only be influenced by surface properties.

The surface properties of the photocatalyst play an important role as heterogeneous photocatalytic reactions usually take place at the interface of solid/liquid or solid/gas phases. The large surface of the foam structure is apparently very effective due to the fact that the photoassisted oxidation of NO in the gas phase requires the adsorption of the reactants at the $\mathrm{TiO}_{2}$ surface. The amount of adsorbed substances increases in the $\mathrm{TiO}_{2}$ foam and thus enhancing the photocatalytic process.

\section{Conclusions}

Titanium dioxide foam was prepared by a simple mechanical stirring method. The obtained $\mathrm{TiO}_{2}$ foam has been characterized using X-ray powder diffraction and SEM. The crystal structure of the $\mathrm{TiO}_{2}$ foam remains unchanged as compared with the initial $\mathrm{TiO}_{2}$ particles. The SEM investigations showed very rough and porous surface structures of the $\mathrm{TiO}_{2}$ foam. These macroporous/mesoporous foams were used to measure the photoassisted degradation of NO according to ISO 22197-1. The photocatalytic properties of the $\mathrm{TiO}_{2}$ foam, compared to those 


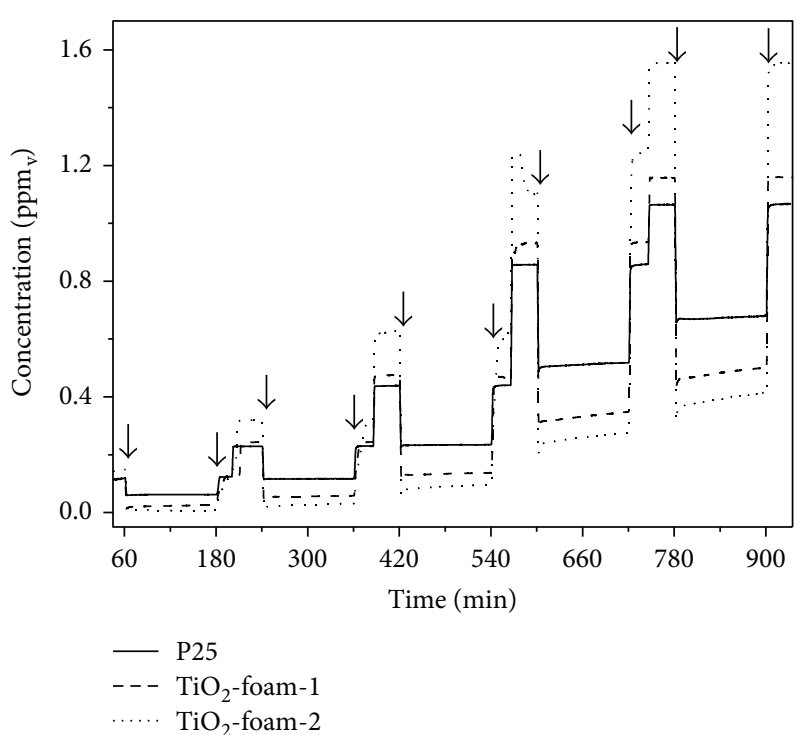

(a)

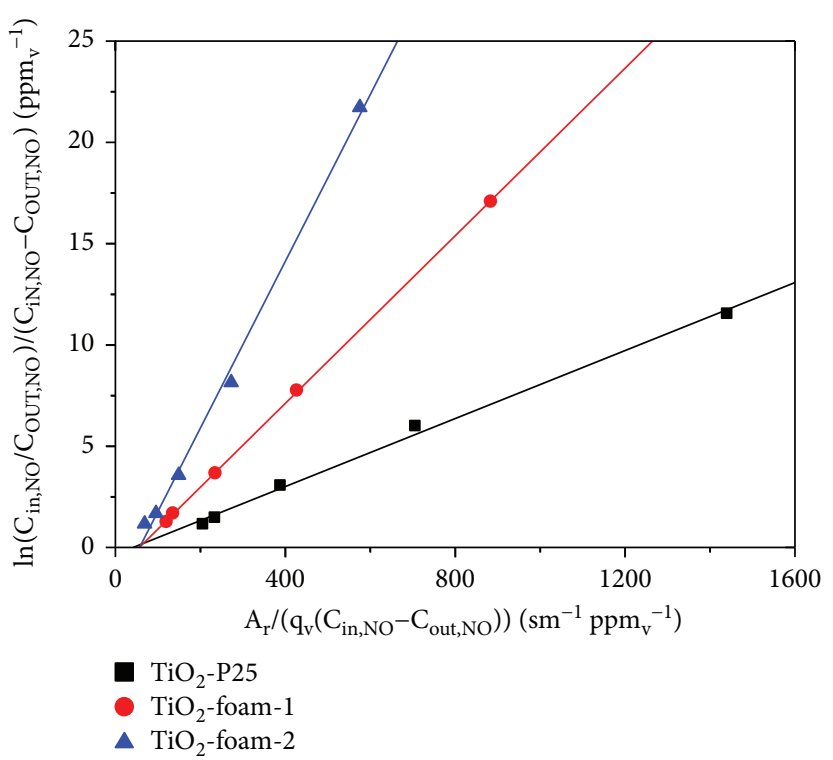

(b)

FIGURE 6: (a) Concentration changes of $\mathrm{NO}$ at the reactor outlet observed during three typical experimental run for a $\mathrm{AEROXIDE} \mathrm{P25,} \mathrm{TiO}_{2}$ foam-1 (with hexylic acid), and $\mathrm{TiO}_{2}$-foam-2 (with hexylamine) as a function of UV illumination. The arrows indicate switching on and off the radiation source. (b) The data analysis according to (4).

of the original photocatalyst powder, improved significantly and increased by about $135 \%$. The photocatalytic properties of $\mathrm{TiO}_{2}$ materials do not only depend on their chemical composition but also on their geometrical microstructure. The porous structure is an attractive way to achieve high photocatalytic activities.

\section{Conflicts of Interest}

The authors declare that they have no conflicts of interest.

\section{Acknowledgments}

The authors thank F. Steinbach (PCI) Leibniz Universität Hannover for his support during the SEM measurements and M. Jahns and A. Mohmeyer (ACI) Leibniz Universität Hannover for their support during the $\mathrm{N}_{2}$ sorption measurements. The authors also thank Dr. D. H. Taffa from Carl von Ossietzky Universität Oldenburg for the XPS measurements. Maryam Jami would like to thank Hannover School for Nanotechnology for her doctoral scholarship.

\section{Supplementary Materials}

Supplementary 1. Fig. S1: (a) SEM photographs of $\mathrm{TiO}_{2}-\mathrm{P} 25$ (Evonik AEROXIDE P25) with different magnifications. (b) SEM photographs of $\mathrm{TiO}_{2}$-foam-1 (hexylic acid as amphiphilic molecule) with different magnifications. (c) SEM photographs of $\mathrm{TiO}_{2}$-foam-2 (hexylamine as amphiphilic molecule) with different magnifications. Supplementary 2. Fig. S2: comparison between the diffuse reflectance spectra of $\mathrm{TiO}_{2}-\mathrm{P} 25$ and prepared $\mathrm{TiO}_{2}$ foam. Inset shows the modified Kubelka-Munk function versus the photon energy of these two samples. Supplementary 3. Fig. S3: left: nitrogen adsorption-desorption isotherm of $\mathrm{TiO}_{2}$-foam-1 (hexylic acid as amphiphilic molecule), $\mathrm{TiO}_{2}$-foam-2 (hexylamine as amphiphilic molecule), and $\mathrm{TiO}_{2}-\mathrm{P} 25$; right: the $\mathrm{BJH}$ graphs indicated corresponding pore size distributions of samples. Supplementary 4. Fig. S4: comparison between the XRD pattern of $\mathrm{TiO}_{2}$ foam (with hexylic acid) and commercial used $\mathrm{TiO}_{2}$ (Evonik AEROXIDE P25). Fig. S5: XRD patterns of $\mathrm{TiO}_{2}-\mathrm{P} 25, \mathrm{TiO}_{2}$-foam-1, and $\mathrm{TiO}_{2}-$ foam-2, the respective reflection peaks of anatase (A) and rutile (R) phases are labeled with their Miller indices. (Supplementary Materials)

\section{References}

[1] M. R. Hoffmann, S. T. Martin, W. Choi, and D. W. Bahnemann, "Environmental applications of semiconductor photocatalysis," Chemical Reviews, vol. 95, no. 1, pp. 6996, 1995.

[2] X. Chen and S. S. Mao, "Titanium dioxide nanomaterials: synthesis, properties, modifications, and applications," Chemical Reviews, vol. 107, no. 7, pp. 2891-2959, 2007.

[3] A. O. Ibhadon, G. M. Greenway, Y. Yue, P. Falaras, and D. Tsoukleris, "The photocatalytic activity of $\mathrm{TiO}_{2}$ foam and surface modified binary oxide titania nanoparticles," Journal of Photochemistry and Photobiology A: Chemistry, vol. 197, no. 2-3, pp. 321-328, 2008.

[4] L. Chen, C. Huang, G. Xu, S. L. Hutton, and L. Miao, "Macroporous $\mathrm{TiO}_{2}$ foam with mesoporous walls," Materials Characterization, vol. 75, pp. 8-12, 2013.

[5] K. Skalska, J. S. Miller, and S. Ledakowicz, "Trends in $\mathrm{NO}_{x}$ abatement: a review," Science of The Total Environment, vol. 408, no. 19, pp. 3976-3989, 2010.

[6] Z. Wu, Z. Sheng, Y. Liu, H. Wang, N. Tang, and J. Wang, "Characterization and activity of Pd-modified $\mathrm{TiO}_{2}$ catalysts 
for photocatalytic oxidation of NO in gas phase," Journal of Hazardous Materials, vol. 164, no. 2-3, pp. 542-548, 2009.

[7] Y. Ohko, Y. Nakamura, A. Fukuda, S. Matsuzawa, and K. Takeuchi, "Photocatalytic oxidation of nitrogen dioxide with $\mathrm{TiO}_{2}$ thin films under continuous UV-light illumination," The Journal of Physical Chemistry C, vol. 112, no. 28, pp. 10502-10508, 2008.

[8] T. Ibusuki and K. Takeuchi, "Removal of low concentration nitrogen oxides through photoassisted heterogeneous catalysis," Journal of Molecular Catalysis, vol. 88, no. 1, pp. 93-102, 1994.

[9] R. Dillert, J. Stötzner, A. Engel, and D. W. Bahnemann, "Influence of inlet concentration and light intensity on the photocatalytic oxidation of nitrogen(II) oxide at the surface of Aeroxide $\mathrm{TiO}_{2}$ P25," Journal of Hazardous Materials, vol. 211-212, pp. 240-246, 2012.

[10] R. Dillert, A. Engel, J. Große, P. Lindner, and D. W. Bahnemann, "Light intensity dependence of the kinetics of the photocatalytic oxidation of nitrogen(II) oxide at the surface of $\mathrm{TiO}_{2}$," Physical Chemistry Chemical Physics, vol. 15, no. 48, pp. 20876-20886, 2013.

[11] V. Kalousek, J. Tschirch, D. Bahnemann, and J. Rathouský, "Mesoporous layers of $\mathrm{TiO}_{2}$ as highly efficient photocatalysts for the purification of air," Superlattices and Microstructures, vol. 44, no. 4-5, pp. 506-513, 2008.

[12] U. Diebold, “The surface science of titanium dioxide," Surface Science Reports, vol. 48, no. 5-8, pp. 53-229, 2003.

[13] T. A. Kandiel, R. Dillert, and D. W. Bahnemann, "Enhanced photocatalytic production of molecular hydrogen on $\mathrm{TiO}_{2}$ modified with Pt-polypyrrole nanocomposites," Photochemical \& Photobiological Sciences, vol. 8, no. 5, pp. 683-690, 2009.

[14] S. Sakthivel, M. C. Hidalgo, D. W. Bahnemann, S.-U. Geissen, V. Murugesan, and a. Vogelpohl, "A fine route to tune the photocatalytic activity of $\mathrm{TiO}_{2}$," Applied Catalysis B: Environmental, vol. 63, no. 1-2, pp. 31-40, 2006.

[15] A. L. Linsebigler, A. L. Linsebigler, J. T. Yates Jr., G. Lu, G. Lu, and J. T. Yates, "Photocatalysis on $\mathrm{TiO} 2$ surfaces: principles, mechanisms, and selected results," Chemical Reviews, vol. 95, no. 3, pp. 735-758, 1995.

[16] Y. Wang, J. Li, P. Peng, T. Lu, and L. Wang, "Preparation of $\mathrm{S}_{-} \mathrm{TiO}_{2}$ photocatalyst and photodegradation of L-acid under visible light," Applied Surface Science, vol. 254, no. 16, pp. 5276-5280, 2008.

[17] T. Ohno, M. Akiyoshi, T. Umebayashi, K. Asai, T. Mitsui, and M. Matsumura, "Preparation of S-doped $\mathrm{TiO}_{2}$ photocatalysts and their photocatalytic activities under visible light," Applied Catalysis A: General, vol. 265, no. 1, pp. 115-121, 2004.

[18] S. U. M. Khan, M. Al-Shahry, and W. B. Ingler, "Efficient photochemical water splitting by a chemically modified n- $\mathrm{TiO}_{2}$," Science, vol. 297, no. 5590, pp. 2243-2245, 2002.

[19] R. Asahi, T. Morikawa, T. Ohwaki, K. Aoki, and Y. Taga, "Visible-light photocatalysis in nitrogen-doped titanium oxides," Science, vol. 293, no. 5528, pp. 269-271, 2001.

[20] H. Kisch, L. Zang, C. Lange, W. F. Maier, C. Antonius, and D. Meissner, "Modified, amorphous titania-a hybrid semiconductor for detoxification and current generation by visible light," Angewandte Chemie International Edition, vol. 37, no. 21, pp. 3034-3036, 1998.

[21] A. A. Ismail, A. Hakki, and D. W. Bahnemann, "Mesostructure $\mathrm{Au} / \mathrm{TiO}_{2}$ nanocomposites for highly efficient catalytic reduction of p-nitrophenol," Journal of Molecular Catalysis A: Chemical, vol. 358, pp. 145-151, 2012.

[22] A. A. Ismail, D. W. Bahnemann, and S. A. Al-Sayari, "Synthesis and photocatalytic properties of nanocrystalline $\mathrm{Au}, \mathrm{Pd}$ and Pt photodeposited onto mesoporous $\mathrm{RuO}_{2}-\mathrm{TiO}_{2}$ nanocomposites," Applied Catalysis A: General, vol. 431-432, pp. $62-$ 68, 2012.

[23] J. Tschirch, D. Bahnemann, M. Wark, and J. Rathouský, “A comparative study into the photocatalytic properties of thin mesoporous layers of $\mathrm{TiO}_{2}$ with controlled mesoporosity," Journal of Photochemistry and Photobiology A: Chemistry, vol. 194, no. 2-3, pp. 181-188, 2008.

[24] Y. Zhao, X. Zhang, J. Zhai et al., "Ultrastable $\mathrm{TiO}_{2}$ foams derived macro-/meso-porous material and its photocatalytic activity," Microporous and Mesoporous Materials, vol. 116, no. 1-3, pp. 710-714, 2008.

[25] A. A. Ismail, D. W. Bahnemann, J. Rathousky, V. Yarovyi, and M. Wark, "Multilayered ordered mesoporous platinum/titania composite films: does the photocatalytic activity benefit from the film thickness?," Journal of Materials Chemistry, vol. 21, no. 21, pp. 7802-7810, 2011.

[26] T. A. Kandiel, A. A. Ismail, and D. W. Bahnemann, "Mesoporous $\mathrm{TiO}_{2}$ nanostructures: a route to minimize Pt loading on titania photocatalysts for hydrogen production," Physical Chemistry Chemical Physics, vol. 13, no. 45, pp. 2015520161, 2011.

[27] A. A. Ismail and D. W. Bahnemann, "One-step synthesis of mesoporous platinum/titania nanocomposites as photocatalyst with enhanced photocatalytic activity for methanol oxidation," Green Chemistry, vol. 13, no. 2, pp. 428-435, 2011.

[28] J. I. Langford and A. J. C. Wilson, "Scherrer after sixty years: a survey and some new results in the determination of crystallite size," Journal of Applied Crystallography, vol. 11, no. 2, pp. 102-113, 1978.

[29] ISO 22197-1, Fine Ceramics (advanced ceramics, advanced technical ceramics) - Test Method for Air-Purification Performance of Semiconducting Photocatalytic Materials, Part 1. Removal of Nitric Oxide, Draft International Organization for Standardization, 2007, https://www.iso.org/obp/ui/ \#iso:std:iso:22197:-1:ed-2:v1:en.

[30] A. Engel, A. Glyk, A. Hülsewig, J. Große, R. Dillert, and D. W. Bahnemann, "Determination of the photocatalytic deposition velocity," Chemical Engineering Journal, vol. 261, pp. 88-94, 2015.

[31] M. C. Biesinger, B. P. Payne, A. P. Grosvenor, L. W. M. Lau, A. R. Gerson, and R. S. C. Smart, "Resolving surface chemical states in XPS analysis of first row transition metals, oxides and hydroxides: $\mathrm{Cr}, \mathrm{Mn}, \mathrm{Fe}, \mathrm{Co}$ and $\mathrm{Ni}$," Applied Surface Science, vol. 257, no. 7, pp. 2717-2730, 2011.

[32] G. Ketteler, S. Yamamoto, H. Bluhm et al., "The nature of water nucleation sites on $\mathrm{TiO}_{2}(110)$ surfaces revealed by ambient pressure X-ray photoelectron spectroscopy," The Journal of Physical Chemistry C, vol. 111, no. 23, pp. 8278-8282, 2007.

[33] S. Devahasdin, C. Fan, K. Li, and D. H. Chen, " $\mathrm{TiO}_{2}$ photocatalytic oxidation of nitric oxide: transient behavior and reaction kinetics," Journal of Photochemistry and Photobiology A: Chemistry, vol. 156, pp. 161-170, 2003.

[34] H. Wang, Z. Wu, W. Zhao, and B. Guan, "Photocatalytic oxidation of nitrogen oxides using $\mathrm{TiO}_{2}$ loading on woven glass fabric," Chemosphere, vol. 66, no. 1, pp. 185-190, 2007. 
[35] L. Yang, A. Cai, C. Luo, Z. Liu, W. Shangguan, and T. Xi, "Performance analysis of a novel $\mathrm{TiO}_{2}$-coated foam-nickel PCO air purifier in HVAC systems," Separation and Purification Technology, vol. 68, no. 2, pp. 232-237, 2009.

[36] C. A. Bignozzi, “Topics in current chemistry," in Photocatalysis, Springer-Verlag, Berlin, Heidelberg, 2011. 

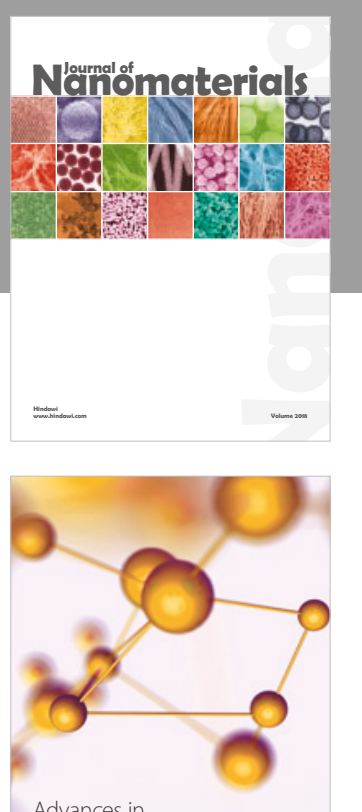

Physical Chemistry
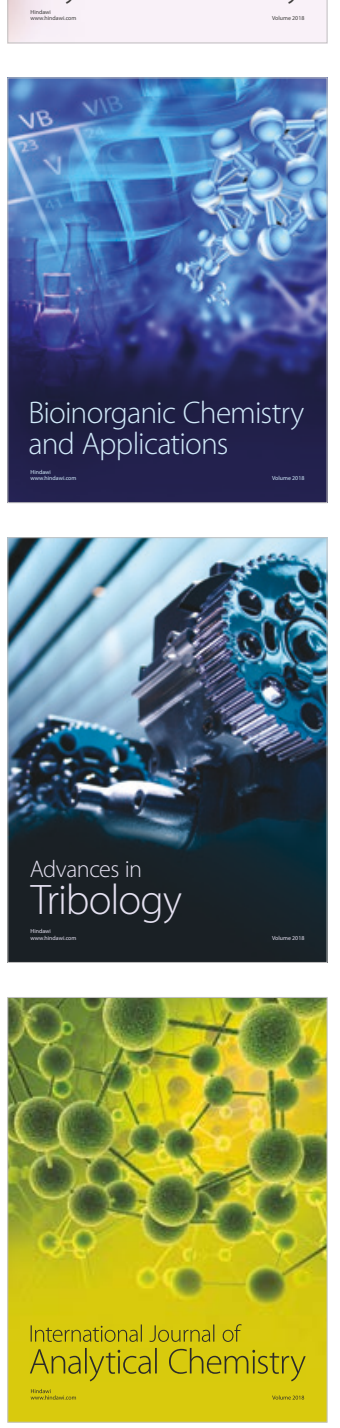

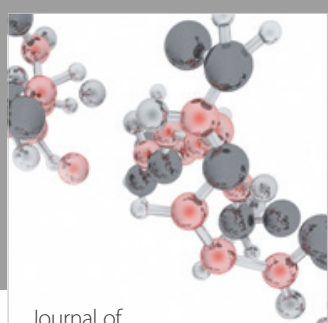

Analytical Methods

in Chemistry

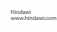

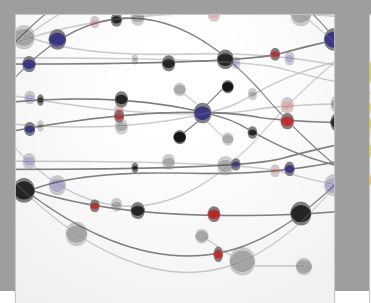

The Scientific World Journal

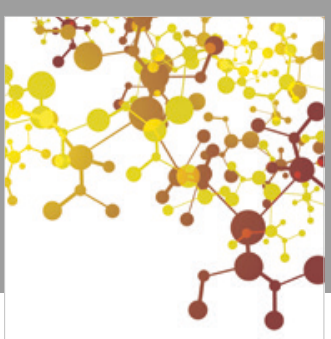

Journal of

Applied Chemistry
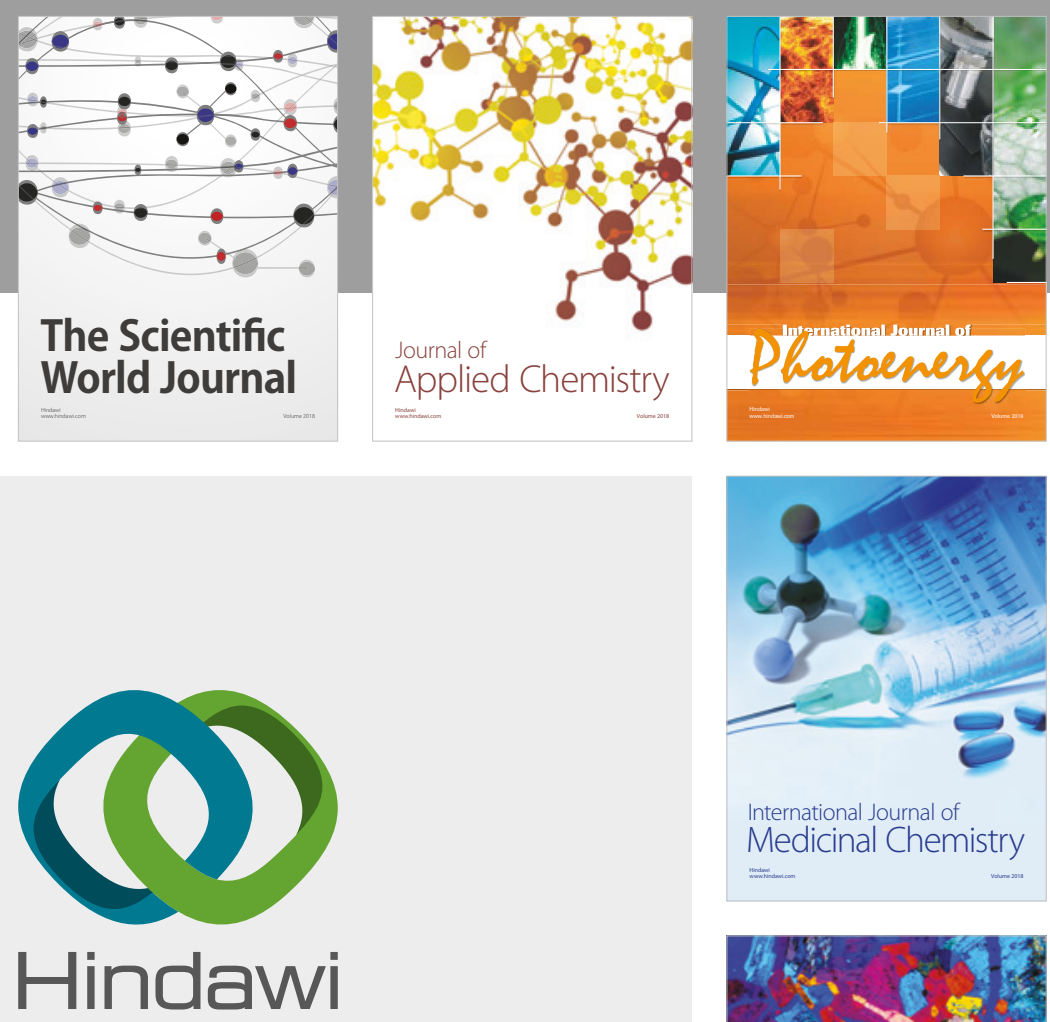

Submit your manuscripts at

www.hindawi.com
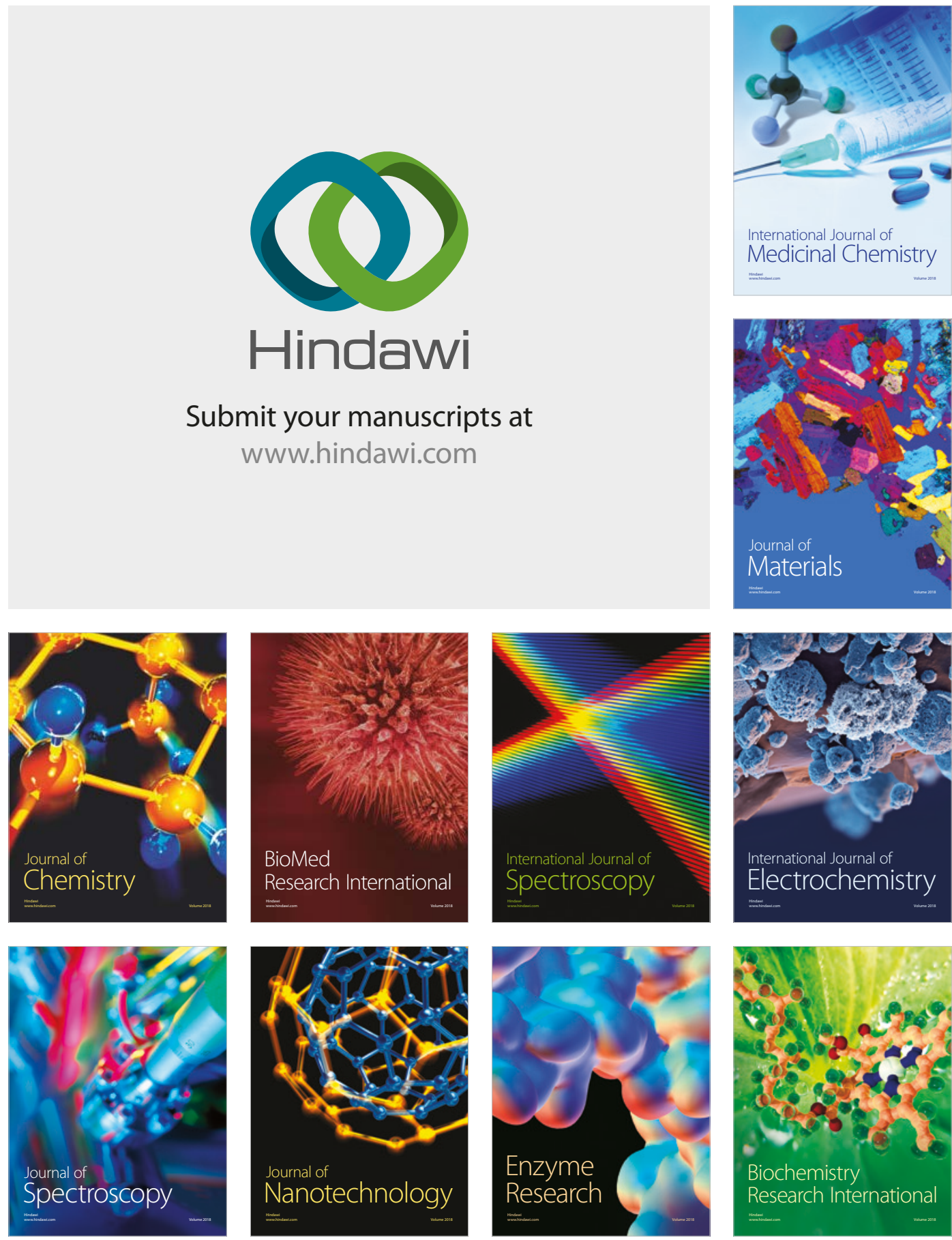
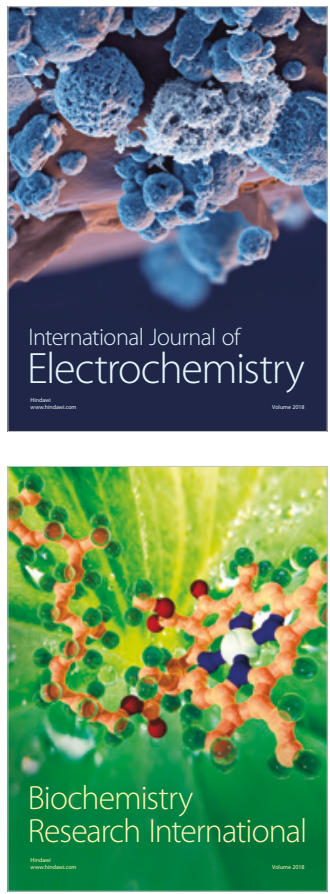